\title{
História do jornalismo em Portugal: proposta de periodização ${ }^{1}$
}

\author{
Jorge Pedro SOUSA ${ }^{2}$
}

Helena LIMA ${ }^{3}$

\begin{abstract}
Resumo:
A periodização sistematiza e ordena diacronicamente os fenómenos históricos, agrupando-os de acordo com denominadores comuns e assinalando continuidades e ruturas evidentes e verificáveis na evolução histórica. Assenta, metodologicamente, num exercício intelectual interpretativo que parte da evidência histórica, embora nunca adira inteiramente à realidade histórica material. O presente trabalho visou, assim, propor uma periodização para a história do jornalismo português, que nunca terá sido esboçada. Definiram-se os seguintes períodos 1) Periodismo artesanal noticioso; 2) Segmentação da imprensa e domínio da imprensa artesanal informativa; 3) Domínio da imprensa artesanal política; 4) Imprensa pré-industrial segmentada; 5) Imprensa industrial segmentada e desenvolvimento dos diários noticiosos de massas; 6) Segmentação mediática do jornalismo, com três fases: a) Máquinas censuradas; b) Disrupção revolucionária; c) Liberalização; e 7) Convergência e fusão.
\end{abstract}

Palavras-chave: Jornalismo. História. Periodização. Portugal.

\section{History of journalism in Portugal: periodization proposal}

\begin{abstract}
:
Periodization systematizes and diachronically orders historical phenomena, grouping them according to common denominators and pointing out evident and verifiable continuities and ruptures in historical evolution. It is methodologically based on an interpretive intellectual exercise that starts from historical evidence, although it never fully attach to material historical reality. The present paper aimed, therefore, to propose a periodization for the history of Portuguese journalism, that never has been outlined. The following periods were defined: 1) Artisanal news press; 2) Segmentation of the press and dominance of informative artisanal press; 3) Dominance of political artisanal press; 4) Segmented pre-industrial press; 5) Segmented industrial press and development of mass daily newspapers; 6) Media segmentation of journalism, with three phases: a) Censored machines; b) Revolutionary disruption; c) Liberalization; and 7) Convergence and fusion.
\end{abstract}

Keywords: Journalism. History. Periodization. Portugal.

\section{Historia del periodismo en Portugal: propuesta de periodización}

\section{Resumen:}

La periodización sistematiza y ordena diacrónicamente los fenómenos históricos, agrupándolos según denominadores comunes y señalando continuidades y rupturas evidentes y verificables en la evolución histórica. Se basa metodológicamente en un ejercicio intelectual interpretativo que parte de la evidencia histórica, aunque nunca se adhiere del todo a la realidad histórica material. El presente trabajo intenta, por tanto, proponer una periodización de la historia del periodismo portugués, que nunca habrá sido esbozada. Se definieron los siguientes períodos: 1) Periodismo artesanal de notícias; 2) Segmentación de la prensa y dominio de la prensa informativa artesanal; 3) Dominio de la prensa política artesanal; 4) Prensa preindustrial segmentada; 5) Prensa industrial segmentada y desarrollo de periódicos de masas; 6) Segmentación mediática del periodismo, con tres fases: a) Máquinas censuradas; b) Disrupción revolucionaria; c) Liberalización; y 7) Convergencia y fusión.

Palabras clave: Periodismo. Historia. Periodización. Portugal.

\footnotetext{
${ }^{1}$ Este trabalho é financiado por fundos nacionais através da FCT - Fundação para a Ciência e a Tecnologia, I.P., no âmbito do projeto PTDC/COM-JOR/28144/2017 - Para uma história do jornalismo em Portugal.

2 Agregado (livre-docente), doutor, professor catedrático da Universidade Fernando Pessoa, investigador integrado do ICNOVA - Instituto de Comunicação da NOVA. Email: jpsousa@ufp.edu.pt..

${ }^{3}$ Helena Lima, doutora, professora associada da Faculdade de Letras da Universidade do Porto. Email: hldlima@gmail.com.
} 


\section{Introdução e referencial teórico}

Periodizar significa categorizar e organizar sequencialmente conjuntos de factos que compartilhem características dominantes, estáveis e diferenciadoras num determinado período de tempo.

As narrativas contam-se entre os fenómenos socioculturais em que mais se nota a tendência para a periodização, pois tendem a obedecer a princípios organizativos que privilegiam a progressão por etapas. Contos, novelas e romances costumam ser divididos em capítulos sequenciais. Os filmes são divididos em cenas sucessivas, tal como ocorre com a Banda Desenhada. As peças teatrais são divididas por atos e cenas consecutivos. A narrativa histórica também pode ser, e normalmente é, organizada por estádios cronológicos - eras, idades, épocas, períodos, fases. Enquanto forma de organizar o discurso histórico, a periodização é uma estratégia dadora de sentido à narrativa histórica. Mas a periodização também pode ser encarada como um instrumento metodológico para a produção de conhecimento em história.

Verdadeiramente, periodizar, além de facilitar e racionalizar o estudo da história, fornece oportunidades para examinar longitudinal e comparativamente sequências de eventos, processos e resultados, os impactos das mudanças históricas e os nexos de causalidade que ligam eventos históricos (LIEBERMAN, 2001). Ao impor uma visão organizada da história pelo recurso a enquadramentos temporais, periodizar afasta a construção do conhecimento histórico da apresentação de uma mera cronologia de eventos dispersos, embora se deva ter em conta que a história é contínua e toda a periodização é arbitrária (GERHARD, 1956; RUESCHEMEYER; STEPHENS, 1997; LIEBERMAN, 2001).

A periodização contribui, portanto, para sistematizar racionalmente os fenómenos históricos, agrupando-os de acordo com denominadores comuns (STEARNS, 2017), que podem, até, ser matematizáveis (LIEBERMAN, 2001; GRININ, 2007). É pois, simultaneamente, um instrumento metodológico e uma síntese do conhecimento histórico, pois permite estabelecer etapas cronológicas que facultam a compreensão do devir histórico, assinalando continuidades e ruturas, sendo usada na história em geral (RAMA, 1968; KULA, 1973; LIEBERMAN, 2001; GRININ, 2007), mas igualmente na história da comunicação e do jornalismo (GODOY, 2008; DALY, 2009). No entanto, é um exercício intelectual interpretativo problemático, já que, mesmo quando fundada na evidência dos nexos de causalidade (RUESCHEMEYER; STEPHENS, 1997; LIEBERMAN, 2001), nunca cola 
inteiramente à realidade histórica material (HAYOT, 2011). É, nomeadamente, difícil definir o início e o fim de um período (DALY, 2009), que são, por norma, impostos arbitrariamente. Gerhard (1956) e Hollander, Rassuli, Jones e Dix (2005), mais finamente, sugerem que a periodização é redutora, dá um falso sentido de progresso à história, recorre, problematicamente, a períodos de curta duração, quando os processos históricos tendem a ser longos e, por vezes, é forçada, gerando inconsistências.

Apesar das objeções e limites à utilização da periodização como método nas ciências históricas, a periodização dos fenómenos históricos jornalísticos ${ }^{4}$ poderá ser útil, já que permite reconhecer que, em cada período determinado de tempo, o jornalismo possuiu certas características diferenciadoras. Essa perspetiva tem como corolário a ideia de que cada período na história do jornalismo produziu, necessariamente, determinados meios, processos, tipos, formas e conteúdos jornalísticos, de acordo com as circunstâncias (culturais, económicas, tecnológicas, sociais, nomeadamente institucionais e políticas) do momento, independentemente da maior ou menor relevância dos acontecimentos particulares e das ações individuais.

Curiosamente, a pesquisa bibliográfica revelou que nunca terá sido esboçada uma periodização da história do jornalismo em Portugal, embora existam tentativas de periodização da história específica da imprensa portuguesa, uma delas global (SOUSA; LIMA; HOHLFELDT; BARBOSA, 2017), outras restritas ao tempo da Monarquia (TENGARRINHA, 1965, 1989, 2013; SOUSA, 2017) e ainda outra incidindo somente no tempo que medeia entre 1968 e 2004 (FAUSTINO, 2004).

A presente pesquisa visou suprir essa lacuna, propondo uma periodização para a história do jornalismo português e usando, por consequência, a periodização como instrumento metodológico para a construção do conhecimento histórico.

\section{Estado da questão}

Em Portugal, vários autores têm, por vezes sem explicitação, usado a periodização da história da imprensa, simultaneamente, como princípio de organização discursiva da narrativa histórica e instrumento metodológico, numa tendência que vem do século XIX. António Xavier da Silva Pereira $(1895,1897)$, o primeiro dentre eles, identifica sete períodos na história da imprensa portuguesa:

\footnotetext{
${ }^{4}$ Entendendo-se, aqui, o jornalismo num sentido amplo do termo, como uma atividade de produção e difusão à escala social de notícias, ideias e outras informações por meios apropriados.
} 
1) Infância da imprensa portuguesa (1625 a 1750);

2) Época Pombalina (1750 a 1807);

3) Dominação estrangeira (1807 a 1820);

4) Lutas entre absolutistas e constitucionais (1820 a 1833);

5) Lutas entre cartistas e setembristas (1833 a 1851);

6) Regeneração (1851 a 1861); e

7) Reinado de D. Luís I (1861 a 1889).

Joaquim Salgado (1945) considera somente três períodos na história da imprensa portuguesa: o primeiro, de predomínio da imprensa noticiosa, que se prolonga até à Revolução Liberal (1822); um segundo, que corresponde ao aparecimento, predominância e posterior crise da imprensa política e partidária (1822-1864); e o terceiro, correspondente ao aparecimento e gradual predominância dos jornais de informação geral pertencentes a grandes empresas, no seio de um sistema capitalista (1864 em diante).

José Tengarrinha $(1965,1989)$, que se limita ao tempo da Monarquia, periodiza a história da imprensa portuguesa em três etapas:
1) Primórdios, até 1820 ;
2) Imprensa romântica ou de opinião (1820-1864);
3) Imprensa industrial.

A história da imprensa de Tengarrinha (1965, 1989), com duas edições, termina na imposição da República, em 1910. Na sua Nova História da Imprensa Portuguesa, Tengarrinha (2013) detém-se em 1865. Nesta obra, mantendo, grosso modo, a sua periodização, associa de uma forma mais fina a evolução da imprensa aos regimes políticos e aos governos que Portugal experimentou, sobretudo entre 1820 e o final do século XIX.

Jorge Pedro Sousa (2017), reportando-se, também, exclusivamente à história da imprensa na Monarquia, propõe os seguintes períodos:

1) Imprensa artesanal primitiva (século XVII-1715);

2) Estabilização e segmentação da imprensa (1715-1820);

3) Domínio da imprensa arcaica de opinião (1820-1851); 
4) Domínio da imprensa política partidária (1851-1864);

5) Domínio da imprensa noticiosa industrial profissionalizada (1865-1910).

Paulo Faustino (2004, p. 202-206) identifica cinco períodos na evolução da imprensa, mas reporta-se, somente, aos anos entre 1968 e 2004:

1) Período marcelista (1968-1974);

2) Período pós-revolucionário (1974-1975);

3) Transição (1976-1985);

4) Reprivatização (1985-1995);

5) Consolidação do sistema de grupos económicos monomediáticos ou multimediáticos (1995-2004).

$\mathrm{Na}$ única tentativa de estabelecer uma história da imprensa periódica portuguesa dos seus primórdios à atualidade, Sousa, Lima, Hohlfeldt, Barbosa (2017) periodizam esta história de acordo com os regimes políticos (Monarquia, I República, Ditadura e Estado Novo e III República), que é uma das maneiras de periodizar a história da comunicação (ROMÁN PORTAS, 2000).

Em conclusão, já houve tentativas - relevantes e fundadas na evidência - de periodizar a história da imprensa jornalística portuguesa. Mas não houve, aparentemente, nenhuma tentativa de periodizar a história do jornalismo português, e a única tentativa de olhar globalmente para a história da imprensa portuguesa estabeleceu uma periodização clássica, em função dos regimes políticos, que, embora pertinente pela relevância que dá às circunstâncias específicas que condicionaram a evolução da imprensa em cada um destes regimes, ignora as potencialidades de uma periodização que parta das características desta mesma imprensa.

\section{Metodologia}

Periodizar, em história, corresponde, conforme se observou, à categorização e agrupamento sequencial de conjuntos de fenómenos que partilham certas afinidades. É um exercício interpretativo de ordenação racional e sequencial dos fenómenos históricos, agrupando-os em conjuntos sucessivos - eras, períodos e as fases - ao longo da diacronia do tempo histórico. Visa dar uma ordem racional e progressiva, ainda que, até certo ponto, 
arbitrária, subjetiva e artificial, ao caos aparente da multitude caleidoscópica de fenómenos históricos.

Um "grande problema" de difícil processamento pelo intelecto humano na sua totalidade, como a sucessão complexa de factos históricos, pode, assim, ser dividido em vários "pequenos problemas" com os quais é possível lidar intelectualmente - os períodos históricos. Essa é uma operação de análise. A periodização em história, na sua essência, parte, assim, da análise. Inicia-se por um processo de racionalização analítica de um problema e, portanto, de redução - ainda que artificial - da sua complexidade, repartindo-o por vários problemas menores. À análise sucede, no entanto, a síntese histórica, já que à categorização dos elementos por afinidades evidentes no meio do caos histórico sucede uma operação de agrupamento sequencial dos conjuntos diacrónicos obtidos (eras, períodos e fases). Narrar a história, desde esse ponto de vista, implica uma análise e uma síntese. Decompõe-se a história em etapas, definidas por continuidades e ruturas (análise), e agrupam-se, seguidamente, estas etapas em sequência diacrónica (síntese).

Periodizar é, ainda, um processo de significação, de atribuição e imposição de sentido ao caos de fenómenos históricos que, à partida, não possuem em si mesmo quaisquer sentidos a não ser aqueles que os agentes históricos neles envolvidos lhes deram e aqueles que resultam da interpretação dos historiadores. Nesta asserção, periodizar é, verdadeiramente, uma operação de outorga de significado e, assim, tem raízes na comunicação. Tal como narrar a história, periodizando-a ou não, o é.

Periodizar facilita a apreensão de dados e a produção de um determinado tipo de conhecimento histórico possível.

Algumas técnicas podem ser usadas para periodizar a história, isoladas ou em conjunto. Hollander, Russuli, Jones e Dix (2005) mencionam as seguintes:

1) Indução, que consiste em partir dos factos históricos dispostos em sequência para, ordenando-os por afinidades, propor a sua segmentação por períodos;

2) Dedução, que ocorre quando se parte de uma hipótese inicial de periodização, elaborada a partir de conhecimento pré-existente, nomeadamente de outras pesquisas, confrontando-a, posteriormente, com os dados encontrados, aceitando-a ou rejeitando-a;

3) Periodização por intervalo "redondo" de tempo, que consiste em estabelecer uma periodização por um intervalo de tempo previamente estipulado, como, por exemplo, um século, ou uma década;

4) Periodização pelo contexto, que consiste em categorizar e sequenciar os 
factos históricos de acordo com as circunstâncias políticas, económicas ou outras (como os regimes políticos); e

5) Periodização por pontos de viragem, que se baseia na identificação de acontecimentos históricos que tenham tido grandes repercussões e provocaram alterações significativas no curso da história, que passam a assinalar o início e/ou o fim de um período.

A metodologia da periodização da história do jornalismo português que aqui se apresenta assentou na categorização dos fenómenos históricos jornalísticos ao longo do tempo, assinalando continuidades e ruturas evidentes e verificáveis na evolução histórica e tendo em conta, conforme sugerem Rueschemeyer e Stephens (1997) e Lieberman (2001), as evidências sobre as correlações de causalidade entre as sequências de factos históricos. Das técnicas assinaladas por Hollander, Russuli, Jones e Dix (2005), recorreu-se, dominantemente, à dedução, já que se partiu do conhecimento pré-existente sobre as características dos meios jornalísticos, ponderando, sobretudo, as mudanças nas estruturas mediáticas, nos meios e nas práticas jornalísticas. Colocou-se, aliás, como grande hipótese unificadora a testar que a confluência verificada nas periodizações de Salgado (1945), Tengarrinha (1965, 1989, 2013), e Sousa (2017) para a história da imprensa portuguesa, com os aportes de Faustino (2004), pode basear a periodização do jornalismo português.

Em certos casos usaram-se pontos de viragem para assinalar novos períodos - como o surgimento do Diário de Notícias para assinalar a entrada no período da imprensa industrial, algo que já tinha sido ensaiado por Tengarrinha $(1965,1989,2013)$. Os regimes políticos foram considerados a título contextual, mas a periodização estabeleceu-se a partir das características dos meios e do jornalismo.

O processo iniciou-se pela consulta e recolha de dados a partir das fontes secundárias que sistematizam e interpretam dados empíricos (TENGARRINHA, 1965, 1989, 2013; FAUSTINO, 2004; SOUSA, 2017; SOUSA; LIMA; HOHLFELDT; BARBOSA, 2017). Seguidamente, atentando-se nas evidências sobre: (a) mudanças estruturais nos media, (b) mudanças nos modos de produção jornalística, (c) alterações nos mecanismos de poder e controlo dos meios jornalísticos, (4) transformações na interação entre jornalismo e vida pública, (5) alterações das práticas e dos processos jornalísticos e (6) mutações nos intérpretes do jornalismo ao longo do tempo, procuraram-se circunscrever períodos históricos para a história do jornalismo português, agrupando-se os fenómenos históricos pela sua afinidade em conjuntos diferenciados e com limites temporais (fase de análise) - os períodos. 
Finalmente, dispuseram-se os períodos "sincrónicos" definidos na fase de análise ao longo do eixo diacrónico do tempo histórico, sequencialmente, numa operação sintética que permite olhar para a história do jornalismo português de uma maneira organizada e sistemática - a periodização (fase de síntese).

\section{Uma proposta de periodização do jornalismo em Portugal}

Um esquema de periodização baseado no conhecimento pré-existente pode revelar-se útil para mapear a evolução do jornalismo português por períodos cronológicos. Conforme se explicitou na metodologia, a proposta aqui desenhada baseou-se na perceção das mudanças que, ao longo do tempo histórico, ocorreram nos media jornalísticos - partindo-se, claro, de uma conceção ampla de jornalismo - e no seu contexto. Os sete períodos propostos para mapear historicamente o jornalismo português, um deles com três fases, sistematizam-se a seguir.

\section{Período 1: Periodismo artesanal noticioso (dos finais do século XVI até 1730)}

Neste período surge a imprensa periódica - de carácter artesanal - em Portugal. Assiste-se à publicação de relações monotemáticas e pluritemáticas ocasionais e dos primeiros periódicos noticiosos português, ainda que de viés propagandístico, a partir de 1641 (Gazeta, Gazeta de Novas Fora do Reino e Mercúrio Português). Surge a figura do "gazeteiro", o noticiarista que, pretendendo narrar a história do presente, é o antepassado direto do jornalista profissional.

Os periódicos vivem de notícias obtidas por cartas (algumas delas dos interessados em aparecerem nas notícias, como diplomatas, homens políticos, militares, etc.), das traduções de peças de periódicos estrangeiros e do que os gazeteiros vão sabendo ou observando.

Os periódicos criam públicos entre as elites, que se habituam a esperar periodicamente por notícias, e contribuem para os primeiros esboços de um espaço público em Portugal.

O poder controla a imprensa por meio de censura prévia (civil e religiosa) e do licenciamento prévio de tipografias e publicações.

Nasce a Gazeta de Lisboa, um periódico noticioso oficioso que se converte na voz pública do poder régio e onde se publicam as leis, regulamentos, nomeações e outros atos administrativos (obedecendo princípio da publicidade), que será o antepassado do diário oficial (o atual Diário da República) 
Período 2: Segmentação da imprensa e domínio da imprensa artesanal informativa (1730-1808)

Período caracterizado pelo aparecimento de periódicos segmentados que se vêm juntar ao oficioso e noticioso Gazeta de Lisboa. Surgem periódicos culturais, científicos e enciclopédicos, comerciais, femininos, jocosos e de crítica social (considerou-se o surgimento do Almocreve das Petas, em 1730, como o início do período), etc. O público que lê a Gazeta de Lisboa é, todavia, normalmente o mesmo que lê os novos periódicos segmentados, num ecossistema dominado pela baixíssima taxa de alfabetização (cerca de $10 \%$ da população) e pela pobreza generalizada. Os novos periódicos tendem a não conquistar novos públicos (tirando, possivelmente, algum público feminino), mas contribuem para sedimentar o público elitista existente.

No geral, as características do sistema "jornalístico" português herdadas do período anterior mantêm-se, incluindo os mecanismos da censura e do licenciamento prévio, que o poder usa para controlar a imprensa.

\section{Período 3: Domínio da imprensa artesanal política (1808-1834)}

Em 1808, periódicos antinapoleónicos inauguram, em Portugal, a imprensa políticoopinativa. O mercado editorial, ao tempo, já está suficientemente consolidado para permitir o surgimento dos primeiros diários portugueses. As necessidades de informação regular, face à instabilidade gerada pelas guerras napoleónicas e pelas invasões francesas, terão, igualmente, contribuído para essa inovação no panorama jornalístico português. Ao mesmo tempo, periódicos políticos e publicistas editados, em clima de liberdade, em Inglaterra, por exilados portugueses (mormente liberais), entram, clandestinamente, em Portugal e estimulam o debate político, que se vai transferindo, crescentemente, para as páginas dos jornais.

Fazer jornalismo, nesse tempo, era, essencialmente, produzir escritos para os jornais políticos ou para os jornais culturais e outros periódicos especializados e mais informativos. Os jornalistas, à época, eram, principalmente, os "políticos de jornal”, os "escritores de jornal" e ainda os publicistas, embora alguns noticiaristas continuassem a produzir informação noticiosa para alguns periódicos, incluindo o oficioso, que se torna oficial, Gazeta de Lisboa (depois publicado com outros títulos).

Após o sucesso da Revolução Liberal de 1820 e da instituição formal da liberdade de 
imprensa em Portugal, os periódicos políticos dominaram a crescentemente segmentada paisagem jornalística portuguesa. O parlamentarismo estimula os políticos em confronto a ampliarem a sua voz para o espaço público por meio de jornais.

Os primeiros jornais políticos e político-publicistas portugueses caracterizam-se, no geral, por serem obras artesanais de indivíduos isolados ou de pequenos grupos que decidiam intervir no espaço público. Sobrevivem pelo financiamento dos interessados e de mecenas, vendas em banca e por assinaturas. Mantidos, escritos e editados por homens políticos, publicistas e, em alguns casos, por literatos, conquistam novos públicos, como a burguesia mercantil e agrícola, cada vez mais desejosa de intervir nos assuntos públicos e adquirir uma bagagem cultural que permitisse esta intervenção sem deslustre. Têm, pois, um importante papel no alargamento e consolidação do espaço público.

O curto regresso ao Absolutismo entre 1823 e 1826, o Miguelismo (1828-1834) e a Guerra Civil (1832-1834) não impediram a circulação de periódicos políticos e publicistas, já que, editados em Inglaterra e noutros países mais livres, circulavam clandestinamente em Portugal.

Em 1826 são fundados dois jornais político-noticiosos que já apontam para uma organização pré-industrial da imprensa: O Português e o Periódico dos Pobres. Este último é o primeiro jornal de baixo preço em Portugal, feito para ser "popular", dentro das circunstâncias difíceis da época (analfabetismo e pobreza).

\section{Período 4: Imprensa pré-industrial segmentada (1834-1864)}

Neste período, particularmente na Regeneração (pós-1851), surgem os jornais políticonoticiosos organizados e representativos de partidos políticos e tendências políticas, entre os quais A Revolução de Setembro, o mais importante diário português do período, afeto, até 1851, aos setembristas e, após 1851, ao Partido Regenerador. Para terem sucesso e corresponderem às crescentes necessidades de informação denotada pelas elites cultas e alfabetizadas, interessadas nos assuntos públicos, que liam a imprensa, os jornais políticos já não se podiam limitar a fazer política. Tinham também de difundir notícias e outras informações, mesmo que fazendo leituras políticas da atualidade.

O parlamentarismo e a liberdade de imprensa, apesar de ameaçada várias vezes até 1851, favoreceram a dinâmica evidenciada pelo setor da imprensa. A constituição dos primeiros partidos políticos portugueses organizados, após 1851, contribuiu para promover o 
surgimento de jornais "de partido" que davam voz pública às posições partidárias.

Os periódicos político-noticiosos de partido dominarão a paisagem mediática portuguesa até 1864. Apresentavam uma estrutura empresarial e redatorial mais sólida e complexa do que os seus antecessores artesanais (excluindo, claro, o artesanal, mas famoso, jornal clandestino $O$ Espetro, publicado durante a guerra civil de 1846-1847). As empresas editoras de certos periódicos, como a empresa de $O$ Panorama e a empresa de $A$ Revolução de Setembro, contavam mesmo com tipografia própria.

Ao nível da forma e do conteúdo, esses jornais também sofreram alterações que os afastaram dos seus predecessores - formato maior, paginação a três colunas diferente do livro, abundante informação generalista (mesclada, no entanto, com artigos de cariz político, entre os quais sobressaía o artigo de fundo, que fazia as vezes de editorial) e introdução de novos géneros jornalísticos, como o suelto e as gazetilhas. Revistas culturais como O Panorama introduzem a informação iconográfica em Portugal. A Ilustração: Jornal Universal é a primeira revista portuguesa a trazer ao público informação iconográfica, sob a forma de gravuras, sobre acontecimentos da atualidade.

O espaço público consolidava-se, portanto, em torno da imprensa partidária. Os jornais ampliavam os debates parlamentares e facultavam a participação de mais indivíduos no espaço público.

Ao tempo, o setor da imprensa torna-se, por outro lado, cada vez mais diversificado. Os diários político-noticiosos, dominantes, convivem com revistas culturais e informativas e periódicos especializados (alguns destes evoluem para jornais generalistas - casos do Jornal do Comércio e de O Comércio do Porto).

O movimento de publicação de jornais, até aí centrado em Lisboa, Porto e Coimbra, alarga-se, neste período, à generalidade do território nacional.

O jornalista continua a identificar-se com a ideia de político ou escritor de jornal ou ainda com a ideia de publicista.

Período 5: Imprensa industrial segmentada e desenvolvimento dos diários noticiosos de massas (1864-1935)

Numa fase de progressiva industrialização, alfabetização e melhoria do nível de vida das populações urbanas de Portugal, o êxito do Diário de Notícias demonstrou a viabilidade de projetos jornalísticos profissionais, politicamente neutros e independentes, dominados pela 
informação noticiosa e orientados para o lucro. A captação de anúncios publicitários torna-se a principal fonte de receitas dos jornais, em detrimento das vendas em banca e das assinaturas. A publicação de anúncios é estimulada pelas tiragens crescentes e estas devem-se à introdução das rotativas e ao baixo preço por exemplar. O preço baixo dos periódicos possibilita a cada vez mais indivíduos comprarem diariamente um jornal.

A imprensa partidária combativa, político-noticiosa, não deixou, porém, de manter a sua importância, pelo menos até ao final da I República. Os partidos políticos da Monarquia e da República alimentaram os seus jornais. Entre eles, os diários republicanos $O$ Mundo e $O$ Século tiveram grande sucesso. No discurso da imprensa independente noticiosa nota-se, igualmente, a ambição de intervir no espaço público, mas em nome do conjunto da nação e não de uma fação política particular. Ao nível do discurso, nota-se, também, devido ao triunfo da reportagem, uma deriva para o sensacionalismo, para a exploração de novos filões temáticos, como o crime, e, ocasionalmente, os escândalos políticos e sociais. Jornais republicanos, com $O$ Mundo à cabeça, contribuíram para o descrédito da Monarquia ao, desbocadamente e, por vezes, sem grande preocupação pela verdade, exporem escândalos em que estavam envolvidos membros da Família Real.

Vários jornais políticos, com o tempo, converteram-se, para vingarem e serem bemsucedidos, em grandes diários de informação geral. São os casos do Primeiro de Janeiro e do Jornal de Notícias, no Porto, mas também de $O$ Século, em Lisboa. A empresa de $O$ Século tornou-se mesmo um conglomerado mediático que agrupava outras publicações, como a revista semanal ilustrada Ilustração Portuguesa, fundamental para a emergência e consolidação do fotojornalismo no país, que abriu a via para a famosa revista $O$ Século Ilustrado. Outras empresas jornalísticas seguiram a mesma via de $O$ Século e começaram a editar outras publicações na órbita dos jornais, como fez o DN, com a revista Notícias Ilustrado.

Nos jornais e revistas deve assinalar-se o crescente recurso a infográficos, ainda que simples, e fotografias para informar sobre a atualidade, tendência suportada pela entrada de fotojornalistas nas redações e pela adoção de tecnologia de impressão que permitia a publicação conjunta de fotografias e texto escrito.

As grandes empresas jornalísticas tinham poder e, por vezes, geravam lucros significativos. Alguns grandes grupos económicos, fosse para controlarem a informação publicada e terem influência no espaço público, fosse para aumentarem os seus lucros, 
começaram a ter interesse na aquisição dos grandes jornais. O grémio dos moageiros, por exemplo, a dado momento conseguiu deter a propriedade dos dois principais diários portugueses - O Século e o Diário de Notícias.

Os grandes jornais diários que dominam o setor da imprensa, neste período, são todos organizados empresarialmente. A empresa jornalística torna-se o núcleo duro do sistema jornalístico. As redações ampliam-se e, a parir do final do século XIX, passam a acolher o repórter, que se converte em sinónimo de jornalista profissional, apesar da resistência dos "políticos de jornal" e dos "escritores de jornal", que, inclusivamente, no final do século XIX, fundam associações de jornalistas que só admitem para sócios o escol político e literário dos colaboradores da imprensa. Tiveram, no entanto, como contraponto a fundação de associações de classe e mesmo de um sindicato que albergava todos os profissionais da imprensa de Lisboa, nomeadamente os repórteres.

O jornalista profissional distingue-se, assim, cada vez mais, dos "jornalistas por ocupação", dos "escritores e políticos de jornal". Aliás, o Sindicato Nacional dos Jornalistas, fundado no contexto do regime corporativo do Estado Novo, passará a atribuir a carteira profissional de jornalista apenas aos indivíduos que faziam do jornalismo na imprensa, incluindo os fotojornalistas, a ocupação principal, permanente, estável e remunerada. Assim, deu-se o contributo que faltava à separação definitiva entre os profissionais do jornalismo e os colaboradores ocasionais da imprensa. O jornalismo autonomiza-se, definitivamente, como profissão em Portugal.

No final deste período, o golpe militar de 28 de maio de 1926 instituiu a censura prévia, tornando a imprensa numa máquina industrial censurada, ainda que bem oleada. A imprensa colaborou, aliás, na propaganda da Ditadura Militar/Ditadura Nacional e do Estado Novo.

Período 6, fase 1: Segmentação mediática do jornalismo - Máquinas censuradas (19351974)

A imprensa deixa de ser o único meio jornalístico em Portugal, mas continua a ser o principal instrumento de difusão de informação de cariz jornalístico no país. Passa a haver jornalismo na rádio e, depois, na televisão, apesar dos jornalistas destes meios não serem considerados jornalistas pelo Sindicato Nacional dos Jornalistas, que emitia as carteiras profissionais. 
A fundação da Emissora Nacional, estatal, e o início das suas emissões de rádio, regulares, a partir de 1935, é o marco que assinala o novo período.

O primeiro cinejornal, o Jornal Português, começa em 1938.

A fundação da Rádiotelevisão Portuguesa (RTP) e o início das emissões regulares de televisão, a partir de 1957, é também importante.

Num quadro legal de censura prévia, os meios jornalísticos, apesar de serem máquinas industriais noticiosas bem oleadas, são também máquinas censuradas que, ademais, contribuem para a propaganda do Estado Novo.

A partir dos anos 1960 há uma certa tentativa de modernização do jornalismo português. Jovens jornalistas são admitidos. Jornais como o Diário Popular têm práticas inovadoras, manifestadas, sobretudo, na reportagem. Cursos de jornalismo são organizados um curso livre no Instituto Superior de Estudos Ultramarinos, em 1962; um curso profissional do Diário Popular, em 1966; outro do Sindicato Nacional dos Jornalistas, em 1968. É fundada a Escola Superior de Meios de Comunicação Social, privada, onde, em 1971, se iniciou um curso de Jornalismo de três anos, interrompido pelo 25 de Abril, em 1974 (a escola desapareceria definitivamente no início da década de 1980). Alguns jovens cursam cursos superiores de Jornalismo no estrangeiro e trazem para Portugal o que aprenderam (casos de João Gomes e José Lechner, licenciados pela Escola Superior de Jornalismo de Lille, França).

O paradigma do jornalismo de qualidade em Portugal, o semanário Expresso, é fundado em 1973.

Período 6, fase 2: Segmentação mediática do jornalismo - Disrupção revolucionária (1974-1979)

Na sequência da Revolução de 25 de abril de 1974 e da indefinição sobre o rumo do País, o discurso jornalístico tende a radicalizar-se e dramatizar-se, num quadro legal de liberdade de imprensa (promulgada uma nova lei de imprensa). Os jornais portugueses voltam a esgrimir, por vezes com violência, como aconteceu no século XIX e durante a I República, visões políticas opostas. Há saneamentos em algumas redações por motivos políticos. A tomada de posição da extrema-esquerda e dos comunistas em jornais como o Diário de Notícias e $O$ Século leva a oposição democrática a aglutinar-se em jornais como os novos Jornal Novo (independente e do "centrão" pró-democracia), O Tempo (direita), O Jornal (esquerda democrática) e $O$ Diabo (direita populista). A Rádio Renascença vai separar-se, 
com os estúdios do Porto a emitirem para o Norte e o Centro e os de Lisboa a emitirem para a capital e o Sul, até ser devolvida ao Patriarcado. A RTP é instrumentalizada. A partir do triunfo das forças pró-democracia a 25 de novembro de 1975, a situação tende a normalizar-se e distender-se.

Várias empresas jornalísticas pertencentes a bancos e seguradoras são nacionalizadas indiretamente, devido à nacionalização destes setores, em março de 1975. Passam à condição de empresas públicas, controladas pelos governos e, portanto, pelos partidos no governo em cada momento.

Passam a ser considerados jornalistas os indivíduos que desempenham funções jornalísticas na rádio e na televisão, que, até então, não o eram.

Período 6, fase 3: Segmentação mediática do jornalismo - Liberalização (1979-1995)

A chegada ao poder do centro-direita, em 1979, abre caminho à reprivatização dos media estatizados e à liberalização e dinamismo do setor da comunicação social. Novos projetos jornalísticos independentes veem a luz do dia, como o diário sensacionalista Correio da Manhã; o também sensacionalista semanário Tal \& Qual; o diário de qualidade Público, lançado por um dos mais importantes grupos empresariais portugueses, a SONAE; o irreverente semanário conservador $O$ Independente, importantíssimo como jornal de denúncia de escândalos políticos e também como instrumento de abertura do jornalismo português a novos géneros e ideias; e as revistas Grande Reportagem, Visão e Sábado.

Surgem alguns projetos editoriais jornalísticos, de duração relativamente curta (não vingaram), alinhados com os partidos políticos, casos do Portugal Hoje (diário alinhado com o Partido Socialista) e O Diário (alinhado com o Partido Comunista Português). Grandes grupos económicos, alguns com a participação de capital estrangeiro, tomam posição no setor da comunicação social portuguesa.

É neste período que a televisão foi aberta à iniciativa privada, a reboque do movimento prévio das rádios livres. Este dinâmico movimento da sociedade civil criou centenas de rádios ilegais, "piratas", que o Estado foi forçado a aceitar e regulamentar, promulgando uma nova lei da rádio que permitiu o surgimento - desta vez, legal - de numerosas rádios locais e cadeias nacionais de rádios no país. Surge, nesse âmbito, a primeira rádio nacional especializada em informação jornalística, a TSF. No setor da televisão há a assinalar o nascimento da Sic e da TVI. 
A revisão da Constituição, fruto da convergência entre o centro-direita e o Partido Socialista, permite o surgimento de uma instância independente para a regulação do setor mediático, a primeira em Portugal - a Alta Autoridade para a Comunicação Social.

$\mathrm{O}$ vigor do setor da comunicação social leva à contratação de milhares de novos jornalistas e à sua valorização salarial e profissional. É lançado o ensino superior da Comunicação Social/Ciências da Comunicação e do Jornalismo em Portugal, atraindo milhares de jovens, que, paulatinamente, vão ocupar as redações, substituindo os jornalistas "feitos" na tarimba.

\section{Período 7: Convergência e fusão (1995 em diante)}

Após 1995, consolida-se o sistema de grupos no setor da comunicação social. Normalizam-se, por outro lado, as relações entre o poder político e os meios jornalísticos, no quadro de um sistema democrático ocidental, com regulação independente, que passa, em 2006, para a Entidade Reguladora para a Comunicação Social, cujos poderes são mais latos do que aqueles que detinha a sua antecessora, a Alta Autoridade para a Comunicação Social.

A expansão da televisão por cabo leva as emissoras portuguesas a abrir canais informativos. A SIC Notícias é o primeiro.

O digital e a Web revolucionam o jornalismo português. Os meios jornalísticos portugueses, acompanhando as tendências internacionais, migram para a Web e entram em competição com outros provedores de informações (websites, blogues, redes sociais...). Os usuários da Web desabituam-se de pagar pelo acesso à informação, o que traz problemas à sobrevivência do jornalismo. O jornalismo perde o papel privilegiado que detinha enquanto gatekeeper que controlava a informação que chegava ao espaço público. As redes sociais tornam-se aliadas do jornalismo na expansão da informação por meio de estratégias narrativas transmediáticas (desde que se saiba lidar com os algoritmos), mas também se tornam um competidor e uma ameaça à qualidade da informação que circula no espaço público, potenciando, nomeadamente, a desinformação.

O jornalismo na Web torna-se crescentemente hipermédia, obrigando as redações a adaptarem-se, tornando-se multimédia. Nas redações, os jornalistas partilham o lugar com engenheiros informáticos, designers, infografistas, gestores de redes sociais, especialistas em marketing, etc.

$\mathrm{Na}$ Web, termos como imprensa, rádio e TV deixam de fazer algum sentido, já que os 
meios, perdendo identidade, ao tornarem-se crescentemente hipermédia, convergem e fundem-se na Web. O jornalismo reinventa-se, adaptando-se não só à Web, mas também aos dispositivos móveis, e tenta explorar vias diversificadas de produção de informação, quer as potenciadas pelo digital (jornalismo de dados e precisão, jornalismo em realidade virtual, jornalismo 3D, jornalismo transmediático, jornalismo com recurso a realidade aumentada...), quer as formas clássicas de narrar (jornalismo especializado, jornalismo literário...).

Ao mesmo tempo que são cobradas novas competências aos jornalistas, a profissão tende a ser, crescentemente, desempenhada num cenário de precariedade laboral e baixos salários. O modelo de negócio jornalístico tradicional, baseado na geração de receitas pela captação de anúncios publicitários, nascido na Revolução Industrial, entra em crise, pois não encaixa num mundo digital, obrigando as empresas jornalísticas a adotarem velhas e novas fórmulas de captação de receitas, como o recurso a assinaturas, mas também a crowdfunding, mecenato, etc. Os meios que melhor resistem são aqueles que estão integrados em conglomerados empresariais (como o Público, da SONAE) ou em grandes conglomerados mediáticos (Impresa, por exemplo), ou que, devido ao seu perfil editorial, conseguem grande número de assinaturas (como o Expresso e o projeto de webjornal e rádio de tendência liberal Observador).

A obsessão pelo politicamente correto limita a liberdade de expressão nos meios jornalísticos ao mesmo tempo que as redes sociais se tornam um fórum mais propício à expressão livre de ideias, opiniões e informações, que rapidamente, no entanto, resultam em discurso de ódio.

O poder tem dificuldades em controlar a informação nas redes sociais, mas os media estão fragilizados e vulneráveis devido à perda de receitas decorrente da crise do modelo de negócio.

O Estado (leia-se o poder político de turno) mantém presença no setor por meio da RTP e da maioria do capital da agência de notícias Lusa.

Antigos jornais não se adaptaram aos novos tempos e são encerrados (casos dos portuenses $O$ Comércio do Porto e $O$ Primeiro de Janeiro).

Na rádio informativa deve assinalar-se o fenómeno dos podcasts. 


\section{Conclusão}

É possível propor a definição de períodos para a história do jornalismo português, pois identificam-se na caleidoscópica história do jornalismo em Portugal continuidades e ruturas. Dito de outro modo, identificam-se certas regularidades durante determinados intervalos de tempo, que se podem, com abertura de espírito, considerar períodos históricos, por sua vez seguidos de ruturas, que assinalam as transições para novos períodos históricos. Assim os períodos históricos sucedem-se, sem que com isto se pretenda sugerir que a evolução do jornalismo português aponta para uma certa direção, passou de um estádio evolutivo inferior para um superior ou que essa evolução foi linear. Por outras palavras, periodizar a história do jornalismo português não significa considerar que este, ao longo do tempo, evoluiu para melhor, mas somente considerar que evoluiu para algo diferente, para um estádio posterior diverso do anterior. É viável, portanto, com pertinência e evidência, periodizar a história do jornalismo em Portugal, mas com as limitações interpretativas assinaladas. A opção de periodização da história do jornalismo português que aqui se expôs, aliás, não é a única. Mas pode abrir um debate sobre a matéria.

Pode aceitar-se, também, a hipótese colocada: as periodizações de Salgado (1945), Tengarrinha (1965, 1989, 2013), Faustino (2004) e Sousa (2017) são confluentes e permitem sustentar, até certo ponto, a periodização aqui proposta. Esta proposta, no entanto, vai mais longe, pois não atende somente à imprensa, como fizeram os autores citados, mas ao jornalismo em geral, entrando em linha de conta com o desenvolvimento do jornalismo na rádio, na televisão e na Web.

Determinados contributos sobre a periodização do jornalismo noutros países ou no mundo ocidental, aqui expostos, também são relevantes, já que no Ocidente se nota, sustentamos aqui, um certo paralelismo na evolução do jornalismo, no sentido de que o jornalismo passou por um período arcaico; um pré-industrial; um industrial, incluindo-se ou não neste período o aproveitamento de outros meios, devido ao surgimento do radiojornalismo e do telejornalismo; e finalmente, com o digital e a Web, um período de convergência e fusão. 


\section{Referências}

DALY, Chris. The historiography of journalism history. American Journalism, v. 26, n. 1, p. 141-155, 2009.

FAUSTINO, Paulo. A imprensa em Portugal. Transformações e tendências. Porto: Media XXI, 2004.

GERHARD, Dietrich. Periodization in European history. American Historical review, v. 64, n. 4, p. 3-32, 1956.

GODOY, Antonio Checa. Historia de la comunicación. De la crónica a la disciplina científica. Sevilla: Netboblo, 2008.

GRININ, Leonid E. Production revolutions and the periodization of History. Herald of the Russian Academy of Sciences, v. 27, n. 2, p. 150-156, 2007.

HAYOT, Eric. Against periodization; or, on institutional time. New Literary History, v. 42, n. 4, p. 739-756, 2011.

HOLLANDER, Stanley C.; RASSULI, Kathleen M.; JONES, D. G. Brian; DIX, Laura Farlow. Periodization in marketing history. Journal of Macromarketing, v. 25, n. 1, p. 32 41, 2005.

KULA, Witold. Problemas y métodos de la historia económica. Barcelona: Península, 1973.

LIEBERMAN, Evan S. Causal inference in historical institutional analysis. A specification of periodization strategies. Comparative Political Studies, v. 34, n. 9, p. 1011-1035, 2001.

PEREIRA, António Xavier Silva. O jornalismo português. Resenha cronológica de todos os periódicos portugueses impressos e publicados no Reino e no estrangeiro desde o meados do século XVI até à morte do saudoso Rei Senhor D. Luís I, bem como os jornais em língua estrangeira publicados em Portugal durante o mesmo tempo. Extraída do Dicionário Jornalístico Português. Lisboa: Tipografia Soares, 1895.

PEREIRA, António Xavier Silva. Os jornais portugueses. Sua filiação e metamorfoses. Notícia suplementar alfabética de todos os periódicos mencionados na Resenha Cronológica do Jornalismo Português recentemente publicada pelo mesmo autor e agora correta e aumentada. Lisboa: Imprensa de Libano da Silva, 1897.

RAMA, Carlos M. Teoría de la historia. Introducción a los estudios históricos. Madrid, 1968.

ROMÁN PORTAS, Mercedes. Aspectos metodológicos de la historia de la comunicación. Ámbitos, n. 5, p. 119-128, 2000.

RUESCHEMEYER, Dietrich; STEPHENS, John D. Comparing historical sequences: a powerful tool for causal analysis. A reply to John Goldthorpe's "Current issues in comparative 
macro-sociology”. Comparative Social Research, n. 16, p. 55-72, 1997.

SALGADO, Joaquim. Virtudes e malefícios da imprensa. Escorço histórico sobre a origem, evolução e ética do Jornalismo. Porto: Portucalense Editora, 1945.

SOUSA, Jorge Pedro. A imprensa portuguesa durante a Monarquia: das origens a 1910. In: SOUSA, Jorge Pedro; LIMA, Helena; HOHLFELDT, Antonio; BARBOSA, Marialva (org.). Uma história da imprensa lusófona. Portugal. Porto: Media XXI, 2017, p. 13-210.

SOUSA, Jorge Pedro; LIMA, Helena; HOHLFELDT, Antonio; BARBOSA, Marialva (org.). Uma história da imprensa lusófona. Portugal. Porto: Media XXI, 2017.

STEARNS, Peter N.. Periodization in World History: challenges and opportunities. In: WELLER, R. Charles (ed.). 21st-Century Narratives of World History: Global and multidisciplinary perspectives. London: Palgrave Macmillan, 2017, p. 83-109.

TENGARRINHA, José. História da imprensa periódica portuguesa. Lisboa: Portugália, 1965.

TENGARRINHA, José. História da imprensa periódica portuguesa. 2. ed. revista e aumentada. Lisboa: Caminho, 1989.

TENGARRINHA, José. Nova história da imprensa portuguesa: das origens a 1865. Lisboa: Círculo de Leitores, 2013. (Coleção Temas e Debates).

Submetido em 11.01.2021

Aprovado em 11.02.2021 